\title{
Sepulturas intrusivas Salinar y Chimú en la Huaca Herederos Chica, valle de Moche, Perú
}

Sépultures intrusives Salinar et Chimú de la Huaca Herederos Chica, vallée de Moche, Perú

Intrusive Salinar and Chimu burials in Huaca Herederos Chica, Moche valley, Peru

\section{Claude Chauchat y Jean Guffroy}

\section{OpenEdition}

\section{Journals}

Edición electrónica

URL: http://journals.openedition.org/bifea/6204

DOI: $10.4000 /$ bifea.6204

ISSN: 2076-5827

\section{Editor}

Institut Français d'Études Andines

\section{Edición impresa}

Fecha de publicación: 1 septiembre 2003

Paginación: 293-315

ISSN: 0303-7495

\section{Referencia electrónica}

Claude Chauchat y Jean Guffroy, «Sepulturas intrusivas Salinar y Chimú en la Huaca Herederos Chica, valle de Moche, Perú », Bulletin de l'Institut français d'études andines [En línea], 32 (2) | 2003, Publicado el 08 agosto 2003, consultado el 10 diciembre 2020. URL : http://journals.openedition.org/ bifea/6204 ; DOI : https://doi.org/10.4000/bifea.6204

Les contenus du Bulletin de l'Institut français d'études andines sont mis à disposition selon les termes de la licence Creative Commons Attribution - Pas d'Utilisation Commerciale - Pas de Modification 4.0 International. 


\title{
SEPULTURAS INTRUSIVAS SALINAR Y CHIMÚ EN LA HUACA HEREDEROS CHICA, VALLE DE MOCHE, PERÚ
}

\author{
Claude CHAUCHAT*, Jean GUFFROY**
}

\section{Resumen}

La Huaca Herederos Chica es un sitio ceremonial del Período Inicial y Horizonte Temprano, en el área de Caballo Muerto del valle de Moche. Las excavaciones de Claude Chauchat y Luis Watanabe en 1970 y 1972 han llevado al descubrimiento de ocho tumbas intrusivas del período Salinar y una del período Chimú. Los cuerpos en las tumbas Salinar se encuentran extendidos, a veces en el costado. Los ceramios de ofrendas son dispuestos al lado, o más raramente sobre el cuerpo mismo. Grandes tiestos de cerámica y lajas de piedra fueron colocados sobre el cuerpo y, a modo de tapas, sobre los ceramios. Con una sola excepción, las ofrendas de cerámica son ollas de cocina con decoración mínima y huellas de uso (hollín). En la tumba Chimú, el cuerpo estaba flexionado y probablemente amarrado en un fardo.

Palabras claves: Prácticas funerarias, Cultura Salinar, Período Intermedio Temprano, Costa Norte del Perú, Valle de Moche.

\section{SÉPULTURES INTRUSIVES SALINAR ET CHIMÚ DE LA HUACA HEREDEROS CHICA, VALLÉE DE MOCHE, PERÚ}

\section{Résumé}

La Huaca Herederos Chica est un site cérémoniel de la Période Initiale et de l'Horizon ancien dans la zone de Caballo Muerto de la vallée de Moche. Les fouilles de Claude Chauchat et de Luis Watanabe en 1970 et 1972 ont amené à la découverte de huit tombes intrusives de la période Salinar et d'une tombe de la période Chimú. Dans les tombes Salinar les corps sont allongés, parfois sur le côté. Les offrandes de céramiques sont disposées à côté, plus rarement

\footnotetext{
* CNRS, Archéologie des Amériques, UMR 8096, Maison de l'Archéologie et de l'Ethnologie: 21, Allée de l'Université - 92023 NANTERRE CEDEX, Francia. E-mail: claude.chauchat@ wanadoo.fr

${ }^{* *}$ Centre IRD / Orléans: 5, rue du Carbone - 45072 Orléans Cedex 02, Francia. E-mail: jean.guffroy@orleans.ird.fr
} 
sur le corps lui-même. De grands tessons de céramique et des dalles de pierre ont été placés sur les corps, ainsi que sur les vases, comme couvercles. Avec une seule exception, les offrandes de céramique sont des poteries utilitaires portant une décoration minimale et des traces d'utilisation (suie). Dans la tombe Chimú, le corps était replié et probablement attaché à l'intérieur d'un fardeau funéraire.

Mots clés : Pratiques funéraires, Culture Salinar, Période Intermédiaire Ancienne, Côte Nord du Pérou, Vallée de Moche.

\title{
INTRUSIVE SALINAR AND CHIMU BURIALS IN HUACA HEREDEROS CHICA, MOCHE VALLEY, PERU
}

\begin{abstract}
The Huaca Herederos Chica is a ceremonial Initial period and Early Horizon site within the Caballo Muerto area in the Moche Valley, Peru. Excavations by Claude Chauchat and Luis Watanabe in 1970 and 1972 yielded eight intrusive burials of the Salinar period and one of the Chimu period. The bodies in Salinar burials are extended, sometimes on one side, with the ceramic offerings being placed at their side or, more rarely, on the body itself. Large ceramic sherds and stone slabs were placed on the body and, as cover, on the ceramic vases. With one exception the ceramic offerings are cooking pots with minimal decoration and traces of use (soot). In the Chimu burial, the body was flexed and probably tied in a bundle.
\end{abstract}

Key words: Funerary Practices, Salinar Culture, Early Intermediate Period, North Coast of Peru, Moche Valley.

La Huaca Herederos Chica pertenece al complejo de Caballo Muerto, al pie de los Cerros San Lorenzo y La Virgen, en el bajo valle de Moche (Fig. 1). Este sitio es uno de las ocho estructuras monumentales, de forma, dimensiones y épocas varias, que existen en este área de aproximadamente dos kilómetros cuadrados. Más precisamente es parte de una concentración de seis estructuras de orientación más o menos paralela, en el sector sur del complejo (Fig. 2). Su ubicación exacta es $8^{\circ} 04.70^{\prime}$ Sur y $78^{\circ} 55.30^{\prime}$ Oeste. Existen también otros dos montículos más al interior de la zona cultivada del valle, que no han sido examinado detenidamente y que podrían ser más tardíos.

En el curso de varias temporadas de excavación en la Huaca Herederos Chica de 1970 a 1974, fueron descubiertos estructuras arquitectónicas y restos de cerámica del Período Inicial y del Horizonte Temprano. Además, tumbas intrusivas más tardías fueron también excavadas.

Aunque citado por R. Larco Hoyle ya en 1938 bajo el nombre de "grupo Herederos", es solamente en 1970 que se iniciaron las investigaciones en este sitio, en el marco del Chan Chan-Moche Valley Project de la Universidad de Harvard. Descripciones detalladas de las varias estructuras del complejo de Caballo Muerto y de su secuencia de ocupación aparecieron independientemente en las tesis de L. Watanabe (1976) y T. Pozorski (1976). Más tarde, este último publicó en un artículo un resumen de su tesis (Pozorski, 1983). La edificación de los Monumentos de Caballo 


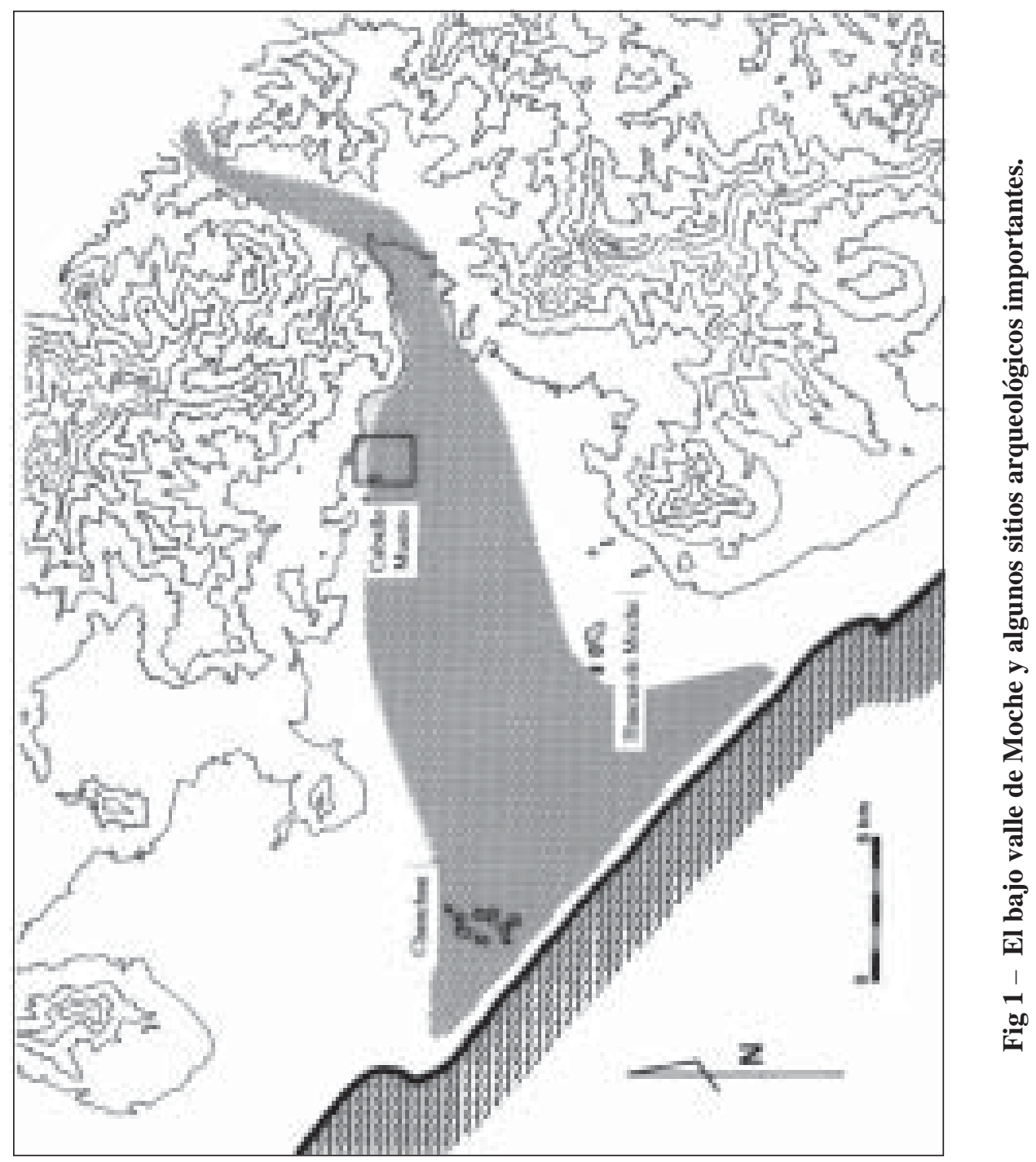




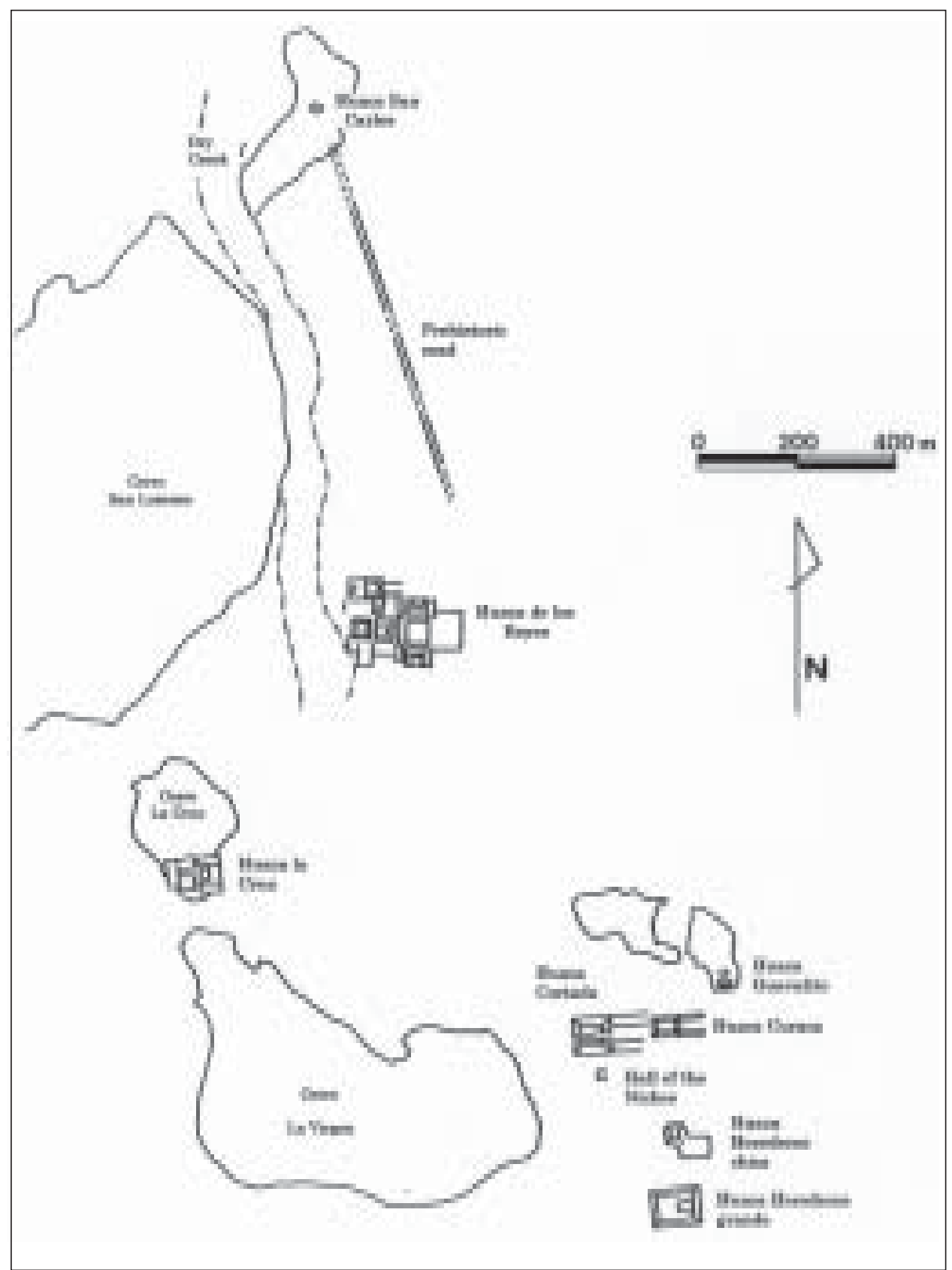

Fig. 2 - El complejo arqueológico de Caballo Muerto (dibujo: cortesía T. y S. Pozorski). 
Muerto empezaría anteriormente a 1500 BC y terminaría hacia 400 BC. Empero, se debe señalar en la superficie de varios de los montículos la presencia de vestigios de épocas más tardías (culturas Salinar, Moche y Chimú), manifestando una ocupación por los menos esporádica de la zona en épocas posteriores.

\section{LAS INVESTIGACIONES}

El sitio fue visitado por primera vez por C. Chauchat en julio de 1970 durante un primer reconocimiento del área de Caballo Muerto. Fue inventariado en esta oportunidad según el sistema provisional empleado por el Chan Chan-Moche Valley Project con el número K498586. Este sistema de numeración es geográfico: la letra inicial designa un "cuadrado" de 10 minutos de longitud y latitud y las divisiones en este cuadrado son aquí 498 y 586. Esto permite ubicar en el mapa un cuadrado cuya superficie es más pequeña mientras el número de cifras es más grande. En el curso del primer examen del sitio se descubrió, en superficie, una rica concentración de tiestos de cerámica de excepcional calidad, perteneciendo sin duda alguna al Horizonte Temprano, destacando la abundancia de decoración con grafitado y, en otra zona del sitio, un pozo de huaquero mostrando un muro de adobes formando una esquina redonda. Son estos dos lugares que fueron excavados en prioridad por C. Chauchat durante la primera temporada de excavación en octubre de 1970 y, con la ayuda de L. Watanabe, durante la segunda temporada en 1972. Una tercera campaña de excavación fue emprendida en 1973 por T. y S. Pozorski en el marco de un estudio general de los sitios formativos de Caballo Muerto. Estos trabajos permitieron establecer la existencia de una probable estructura en forma de U que puede ser fechada del Horizonte Temprano y que fue construida encima de otras estructuras, de naturaleza diferente, que datan del Período Inicial. En el curso de todas estas excavaciones fueron también encontradas varias tumbas del período Salinar y una sola tumba del período Chimú, de las cuales únicamente la tumba encontrada por T. y S. Pozorski fue publicada (Donnan \& Mackey, 1978: 40-43). Las excavaciones de Chauchat y Watanabe en 1970 y 1972 permanecían inéditas hasta hoy. Presentaremos en el presente trabajo el análisis de los datos funerarios, mientras la ocupación y los restos arquitectónicos del Período Inicial y del Horizonte Temprano son el tema de otro artículo (Chauchat et al., en preparación).

\section{DESCRIPCIÓN DEL SITIO}

La Huaca Herederos Chica tiene, actualmente, una forma aproximada en L constituida de dos partes: una plataforma más alta, de pequeñas dimensiones y forma cuadrangular, y un montículo más bajo, rectangular alargado, pegado al este de la plataforma alta pero desplazado hacia el sur, y que llamaremos la plataforma oriental (Fig. 3). Esta disposición evoca otras estructuras del mismo período que tienen una conformación en U compuesta de una plataforma alta situada al oeste y dos alas más bajas hacia el este, flanqueando una serie de patios escalonados bajando en dirección este. El ejemplo más conocido en la zona de Caballo Muerto es la Huaca de los Reyes. En el caso de la Huaca Herederos Chica, se puede suponer la existencia original de una ala norte pegada simétricamente a la plataforma alta. Esta parte del sitio habría sido 
destruida en la primera mitad del siglo XX, durante la mecanización del cultivo de la caña de azúcar, cuyos campos rodean totalmente el sitio.

\section{LAS EXCAVACIONES}

Los trabajos de excavación han afectado tres sectores, distantes de una decena de metros uno de otro, en tres áreas distintos del sitio (Fig. 3). Los sectores I y III han proporcionado tumbas intrusivas, mientras los trabajos llevados a cabo en el sector II han sido solamente de limpieza del talud de la plataforma. Estas excavaciones en 1970 y 1972 han sufrido de la falta de experiencia de algunos participantes, particularmente el autor principal, y también de la falta de algunos medios indispensables para la excavación de tumbas como lo son herramientas finas y un producto de consolidación y conservación de los huesos. Esta situación no ha permitido que la posición de los esqueletos de algunas tumbas sea correctamente documentada pero se debe agradecer particularmente los esfuerzos de J. Vreeland para la tumba $\mathrm{n}^{\circ} 6$ y A. Paulet para la tumba $\mathrm{n}^{\circ}$ 9. Asimismo, un estudio detallado de antropología física fue imposibilitado por el estado fragilísimo de los huesos, a pesar de algunas observaciones de J. Dricot que detallaremos en cada caso.

\section{1. Sector I}

En la parte no destruida de la plataforma en esta trinchera, hemos excavado tres tumbas con cerámica del estilo Salinar. Las posiciones relativas de las tumbas pueden apreciarse en la figura 4. Al parecer, estas tumbas habían sido cavadas desde la superficie de la capa 2 del relleno. Eran rectangulares con ángulos redondos y paredes casi verticales, salvo la tumba $n^{\circ} 3$ que tenía una forma más ovalada. La fosa cortaba el relleno en superficie de la plataforma y la plataforma misma. El fondo de la tumba tenía una delgada capa (aproximadamente $2 \mathrm{~cm}$ de espesor) de arena fina sobre la cual fueron depositados los cadáveres y el ajuar funerario. El relleno de las tumbas está formado por la tierra y el barro extraidos de las fosas y contiene tiestos característicos del Período Inicial y Horizonte Temprano, así como algunos del estilo Salinar.

\section{1. 1. Tumba $n^{\circ} 1$}

La fosa tenía $1,30 \mathrm{~m}$ de largo por 0,60 $\mathrm{m}$ de ancho y 1,40 $\mathrm{m}$ de profundidad. $\mathrm{Su}$ eje de orientación era Este-Oeste (Fig. 5, $n^{\circ} 1$ ). No se encontró vestigios oseos en la fosa misma sino en un nicho excavado en el fondo de la fosa y el rincón noroeste. Estos huesos, removidos por una causa desconocida, pertenecían a un esqueleto de recién nacido. El acceso al cuerpo era protegido por un tiesto de cerámica grande apoyado verticalmente a la entrada del nicho. El ajuar funerario se compone de cuatro ollas de cuello expandido y decoración de líneas blancas verticales con sendas tapas formadas por tiestos de cerámica. Además, dos de ellas estaban cubiertas también por una laja de piedra. Otras piedras estaban también dispuestas en los costados para mantener verticales las vasijas. Obviamente, el cadáver del niño fue metido primero en la tumba y después las vasijas. En cuanto a las vasijas, que son de tipo utilitario, se debe notar que coexisten dos tipos de decoración, el primero con líneas delgadas 


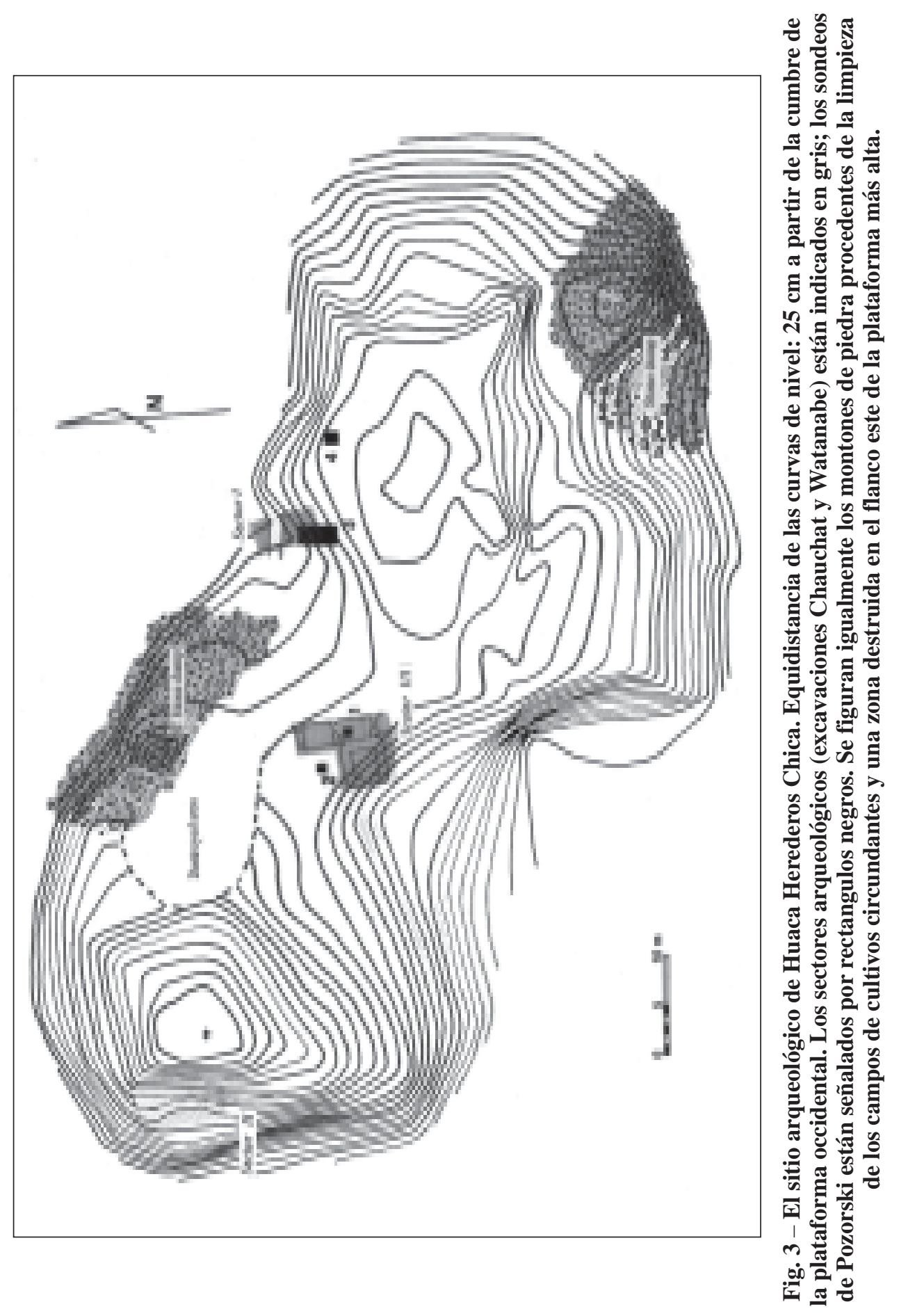



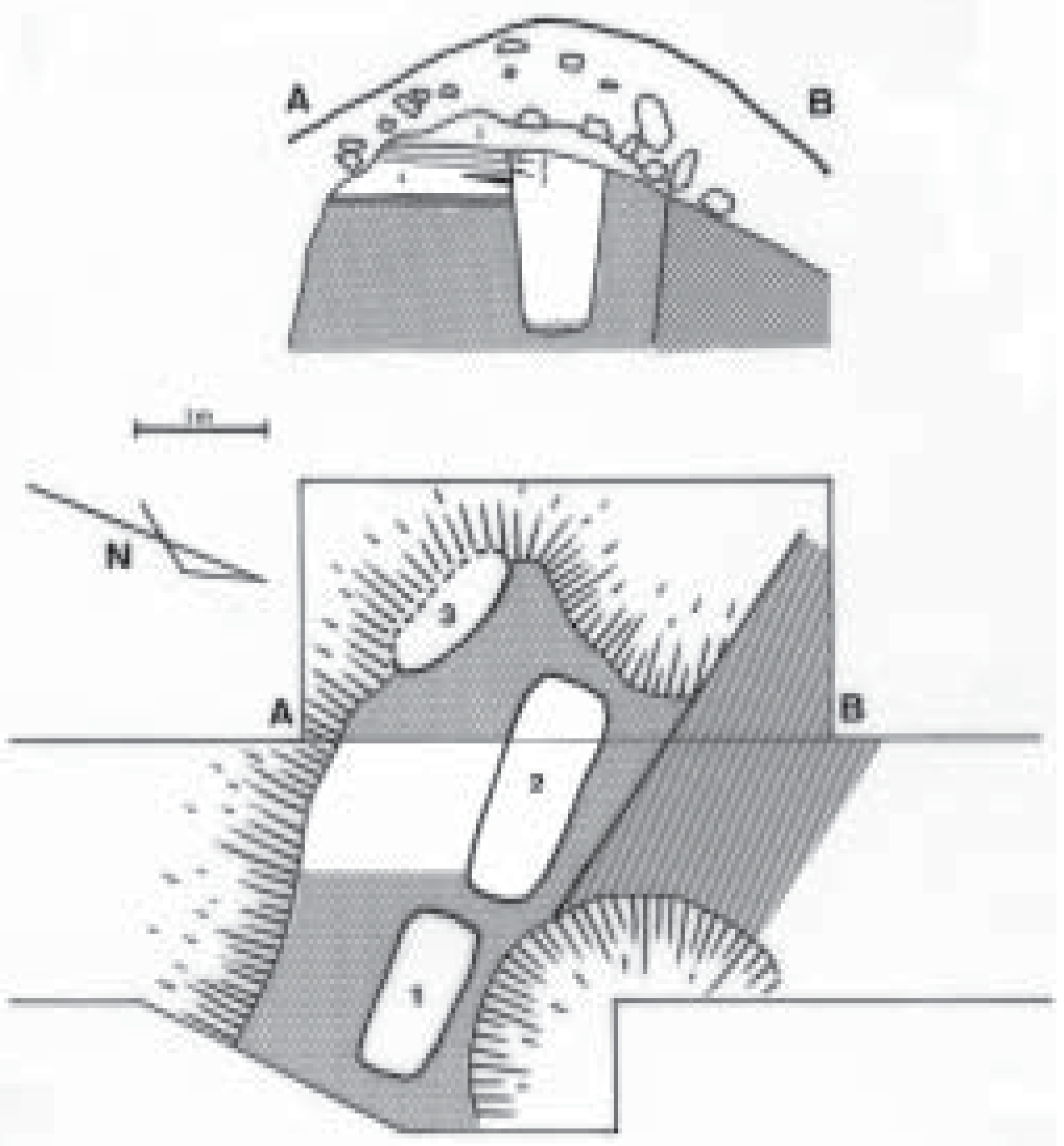

Fig. 4 - Plano y perfil estratigráfico del sector I. En la masa de la plataforma cuya superficie intacta está indicada en punteado, se aprecia la disposición de las tumbas $n^{\circ} 1,2$ y 3. El muro de adobes cónicos limitando el sitio hacia el norte está indicado en plumeado. El área excavado en el suelo de la plataforma ha sido dejada en blanco. Encima, a la misma escala, el perfil estratigráfico según la línea A-B. 

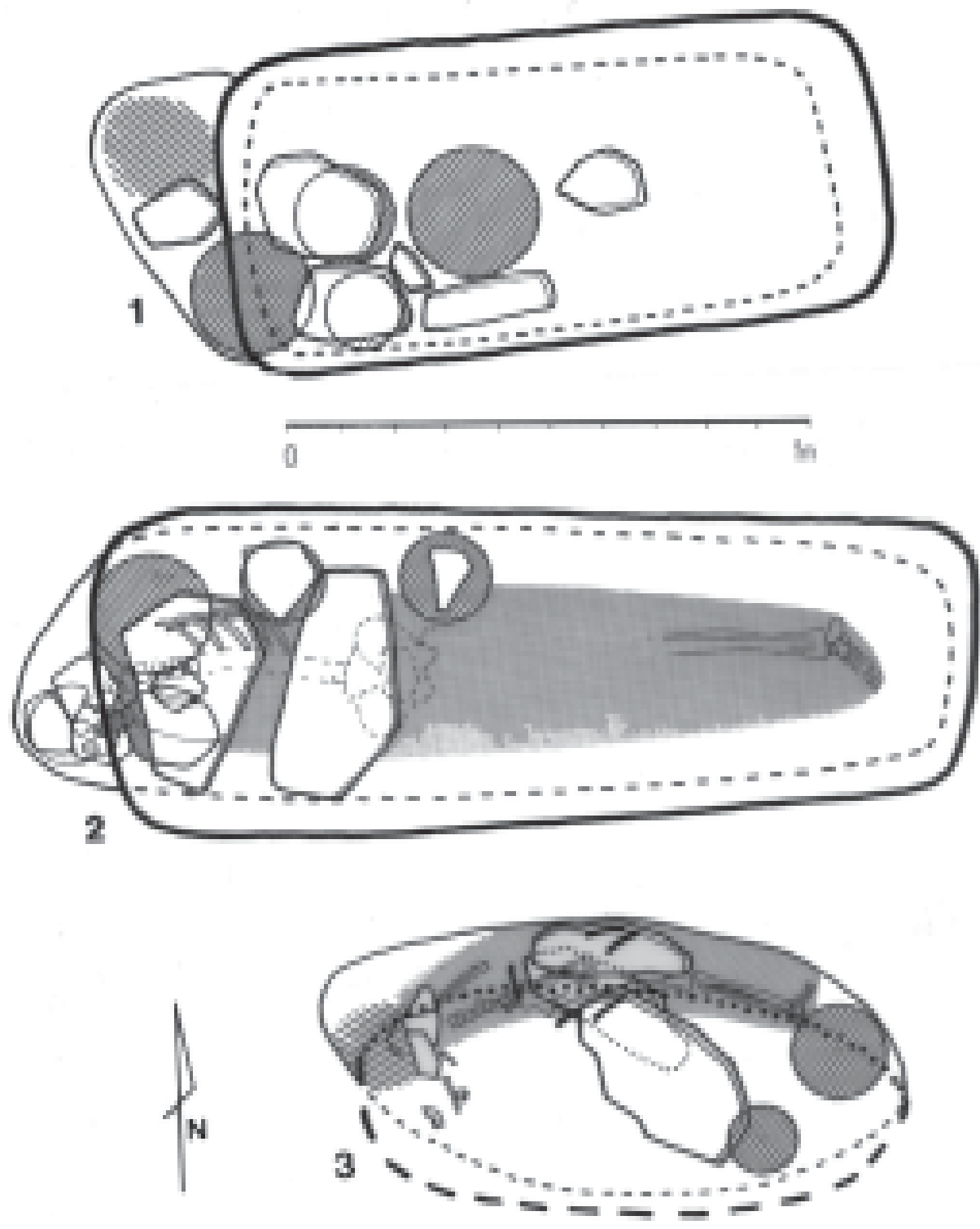

Fig. 5 - Planos de las tumbas del sector I. Se diferencia el contorno de la fosa al nivel de la superficie de la plataforma (trazo grueso) y al fondo (trazo delgado). Los ceramios están representados por su silueta en punteado; los tiestos formando tapas y las lajas de piedra han sido dejadas en blanco. 1: tumba $n^{\circ} 1$; la ubicación del esqueleto de niño recién nacido está señalada por la zona plumeada en la extremidad derecha de la fosa. 2: tumba $n^{\circ} 2$; en gris, la zona ocupada por el esqueleto. 3: tumba $n^{\circ} 3$; la zona plumeada indica el emplazamiento del cráneo; tiestos aislados parados están representados por arcos en trazo grueso. 
(5-8 mm de ancho) agrupadas de tres a más, a veces unidas por puntos blancos en el cuello, el segundo teniendo solamente bandas blancas anchas de $2-3 \mathrm{~cm}$ (Fig. 6, $\mathrm{n}^{\circ} 1 \mathrm{a}$ 4). Aquí, la única vasija con este segundo tipo de decoración es la $n^{\circ} 4$.

\section{1. 2. Tumba $n^{\circ} 2$}

Las dimensiones de la fosa de esta tumba eran de 1,70 $\mathrm{m}$ de largo sobre $0,55 \mathrm{~m}$ de ancho máximo sobre $1,50 \mathrm{~m}$ de profundidad (Fig. $5, \mathrm{n}^{\circ}$ 2). Tenía, como la anterior, un nicho de $20 \mathrm{~cm}$ en la extremidad oeste, esta vez desplazado hacia el sur, donde se encontraba el cráneo del cadáver. La orientación de la fosa era Este-Oeste. El cuerpo es aparentemente de un adulto pero, por falta de tiempo y de herramientas finas se conoce muy poco de su posición en la tumba. Según los apuntes de campo, el cuerpo parecía extendido con el dorso sobre la arena del fondo y los brazos un poco flexionados en ambos lados del torso, la cabeza volteada y la cara mirando hacia el sur. Hay algunas dudas sobre la posición real del cuerpo, dado que los indicios eran muy débiles y que esta posición parece diferente a la de las demás tumbas del período Salinar. Juzgando por la ubicación de los pies, había un espacio suficiente en la fosa como para disponer el cuerpo sin excavar el nicho de la extremidad oeste, lo que significa que la excavación de este nicho es un hecho ritual ex profeso. El cráneo estaba también cubierto con un tiesto grande de cerámica que fue encontrado roto.

Las cuatro vasijas descubiertas en esta tumba comprenden tres ollas de cuello expandido (Fig. $6, n^{\circ} 6,7,8$ ) y una olla carenada de cuello corto y recto, y base plana $\left(n^{\circ} 5\right)$. Ninguna tiene decoración. Se encontraban dispuestas sobre varias partes del cuerpo, una sobre la mano izquierda, dos otras sobre el brazo y el hombro izquierdo, y la cuarta, la olla de cuello recto, sobre el hombro derecho. Al cernir la arena limpia que cubría el fondo de la fosa, se encontró una cuenta de turquesa y un pedazo de colorante rojo (ocre o cinábrio). No se conoce sus ubicaciones respecto al cuerpo y por supuesto no se puede asegurar que formen parte del ajuar funerario, y no, sencillamente, del relleno de la fosa.

\section{1. 3. Tumba $n^{\circ} 3$}

Esta tumba fue encontrada al limpiar los alrededores de la excavación. La parte superior de la fosa estaba ya parcialmente destruida por un pozo de huaquero, encontrándose en la pendiente de este pozo (Fig. 4). La fosa, orientada de Este a Oeste, tenía 1,10 m de largo. Su ancho, que no ha podido ser medido a causa de la destrucción de la pared sur, puede ser estimado en 0,50 m aproximadamente (Fig. 5, $\mathrm{n}^{\circ} 3$ ). La profundidad era de cerca de $1 \mathrm{~m}$. La orientación era de Este a Oeste. La pared intacta de la fosa, en el lado norte, parecía entrar oblicuamente en el depósito, prolongándose así por un nicho en la extremidad oeste. Primero, aparecieron tres lajas de piedra dispuestas horizontalmente en el centro de la fosa, que cubrían parcialmente el tronco del cadáver. Se pudo comprobar que no cubrían ninguna vasija, pues las dos vasijas encontradas en esta tumba estaban dispuestas cerca de la extremidad este. Debajo de las lajas, en la región de la pelvis, se encontraron varios tiestos grandes de cerámica dispuestos verticalmente que, aparentemente no pertenecían a una vasija reconstituible. 

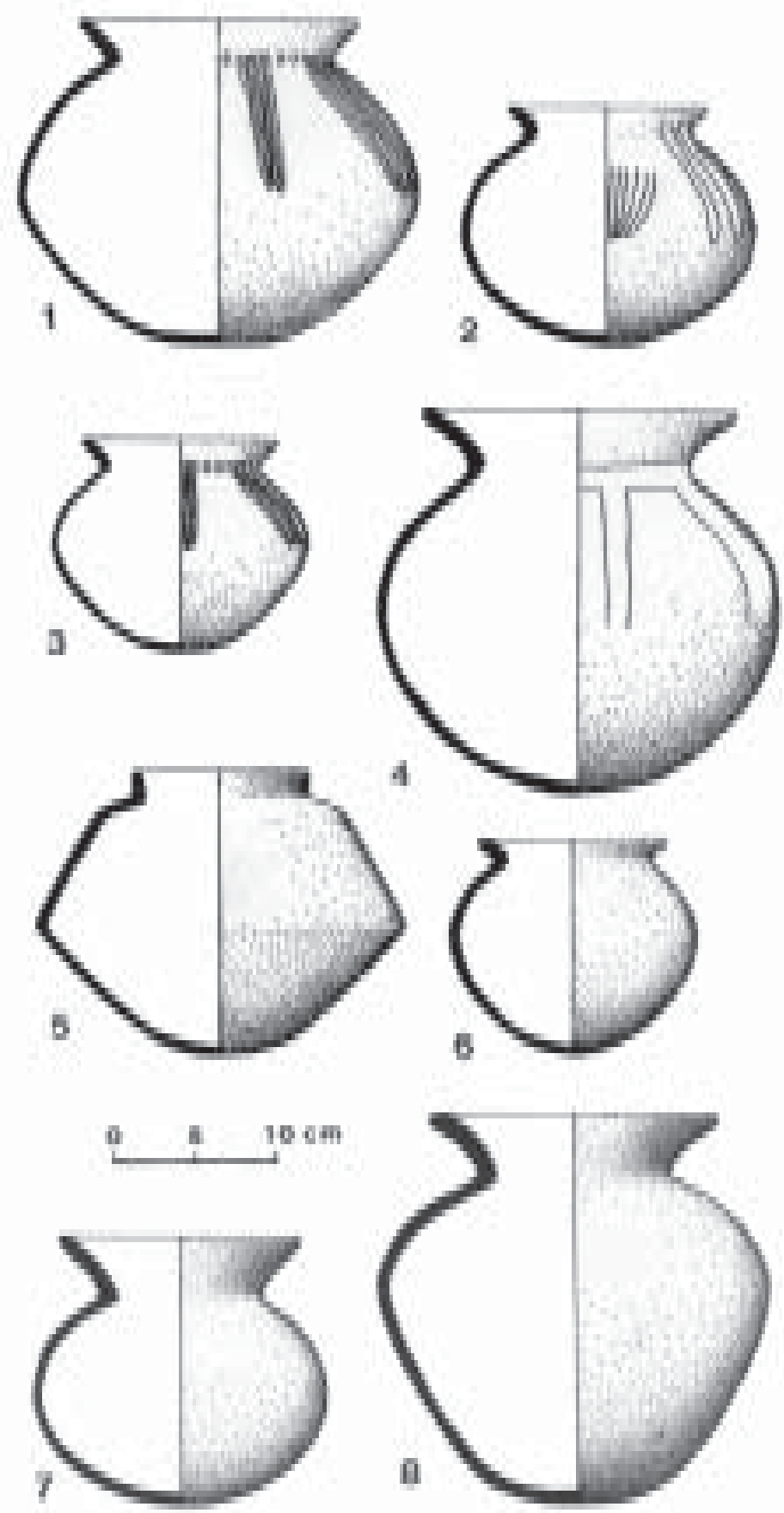

Fig. 6 - Ceramios de la tumba $n^{\circ} 1\left(n^{\circ} 1,2,3,4\right)$ y de la tumba $n^{\circ} 2\left(n^{\circ} 5,6,7,8\right)$. 
Esta inhumación pertenece a un niño de aproximadamente 6 a 8 años, echado y apoyado de perfil contra la pared norte de la fosa (decubito lateral izquierdo), los brazos y las piernas extendidas y el cráneo metido en el nicho occidental. Como en el caso anterior, quedaba un espacio suficiente en la extremidad oriental como para acomodar el cuerpo a lo largo de la fosa sin la necesidad de este nicho. La región de la pelvis ostentaba también improntas de tejido en el sedimento. El cráneo se encontraba como disturbado y roto a pesar de estar protegido por uno o varios tiestos sueltos de cerámica. En su cercanía se encontraron otros pedazos (particularmente dos fragmentos de mandibula) cuyo examen en laboratorio comprobó que pertenecían a dos individuos adultos más. Como en los casos anteriores, las dos vasijas son ollas de cuello expandido del estilo Salinar (Fig. 7). La $\mathrm{n}^{\circ} 1$ tiene bandas blancas delgadas agrupadas por tres y la $\mathrm{n}^{\circ} 2 \mathrm{es}$ del tipo con bandas anchas, unidas esta vez por una ancha banda alrededor del cuello. Es posible que esta tumba haya sido parcialmente saqueada y disturbada por huaqueros.

\section{1. 4. Conclusiones sobre las tres tumbas del sector I}

Primero se debe remarcar la orientación casi paralela de las fosas, su forma alargada, sub-rectangular para las dos primeras, y la presencia de un nicho para recibir la cabeza del cadáver en la extremidad occidental. La primera fosa parece haber sido preparada para recibir un difunto de más edad que el niño ahí enterrado. También en las dos primeras tumbas, se observa la disposición similar de las vasijas, tapadas por tiestos de cerámica y después por lajas de piedra. Esta disposición parece encontrarse disturbada en la tercera tumba. En los tres casos, el ajuar funerario está compuesto principalmente de vasijas utilitarias (ollas) del estilo Salinar, en número de dos a cuatro, aunque es posible que otras hayan sido removidas de la tumba $\mathrm{n}^{\circ} 3$. Estas ofrendas no parecen señalar personajes de alto rango en su sociedad. Por otro lado, todo parece indicar que estos tres enterramientos son muy cercanos en el tiempo.
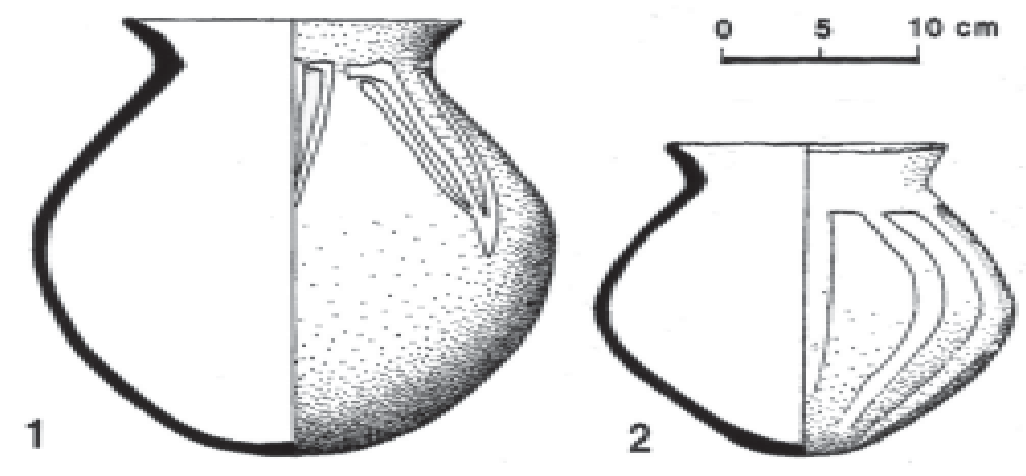

Fig. 7 - Ceramios de la tumba $n^{\circ} 3\left(n^{\circ} 9\right.$ y 10$)$. 
Fue en el sector I, y probablemente en la extremidad suroeste de la trinchera de Chauchat y Watanabe (Fig. 4), que fue encontrada por Pozorski la tumba publicada en Donnan \& Mackey (1978). Se nota la orientación idéntica así como el material de ofrendas similar, aunque en mayor número, pues nueve vasijas sin decorar fueron retiradas de esta tumba.

\section{2. Sector III}

En el sector III, cinco de las tumbas intrusivas encontradas tienen cerámica del estilo Salinar, la sexta tumba perteneciendo al período Intermedio Tardío. Todas se encuentran en la parte norte de la excavación, fuera del recinto cuadrado con esquinas redondas que se excavó en esta área. La figura 8 muestra un plano general de este sector, el borde sur de la plataforma baja que cubría las estructuras del Período Inicial y la distribución espacial de las tumbas en relación con estas estructuras.

\section{2. $1 . \operatorname{Tumba}^{\circ} 4$}

Esta tumba es de un niño de posiblemente 4 a 6 años de edad (Fig. 9 arriba). La fosa es alargada, de orientación Este-Oeste y ligeramente trapezoidal. Mide 0,80 m de largo por 0,35 $\mathrm{m}$ de ancho máximo en la extremidad oeste, donde se encuentra la cabeza del cadáver. El cuerpo se encuentra echado en decubito lateral izquierdo, con las piernas y los brazos extendidos. Un tiesto de cerámica grande se encuentra delante de la cara, quizás caído de su ubicación original sobre la cabeza. El ajuar funerario está constituido de dos vasijas ubicadas, la primera detrás de la cabeza, la segunda más allá de los pies. Estas dos vasijas son ollas de cuello expandido del estilo Salinar, sin decorar (Fig. 10, $\mathrm{n}^{\circ} 1$ y 2 ).

\section{2. 2. La tumba $^{\circ} 5$}

Esta tumba se encuentra inmediatamente al sur de la anterior (Fig. 9 abajo). La fosa, que tiene una forma alargada, está orientada Este-Oeste pero ligeramente en dirección noroeste mientras la anterior estaba ligeramente en dirección sureste. El largo es de 1,60 m con un ancho de cerca 0,50 $\mathrm{m}$ y una profundidad aproximada de $1 \mathrm{~m}$. La extremidad oeste de la fosa ha chocado contra el ángulo redondo noreste del cuarto cuadrado del Período Inicial y lo ha respetado. En la excavación, primero aparecieron dos lajas alargadas de piedra dispuestas transversalmente y cerca de la extremidad occidental de la fosa. Debajo de éstas, se encontraron tiestos de cerámica de tamaño mediano a grande, cubriendo el torso y los brazos del cuerpo. De las observaciones hechas en este momento se desprende que el cadáver estaba echado, por lo menos parcialmente, en decubito dorsal, dado que los brazos estaban ligeramente apartados en ambos lados del torso, sin que se pueda eliminar la posibilidad de una torsión lateral entre el torso y las piernas. La cara daba frente al sur. Cuatro vasijas se encontraban también en la fosa. La más grande depositada más alla de los pies, ocupaba la extremidad este, mientras otra se encontraba aparentemente encima del brazo derecho, y las dos últimas en la extremidad oeste, detrás y sobre la cabeza del cadáver. Tres de estas vasijas son ollas de cuello expandido con decoración pintada en bandas blancas del 


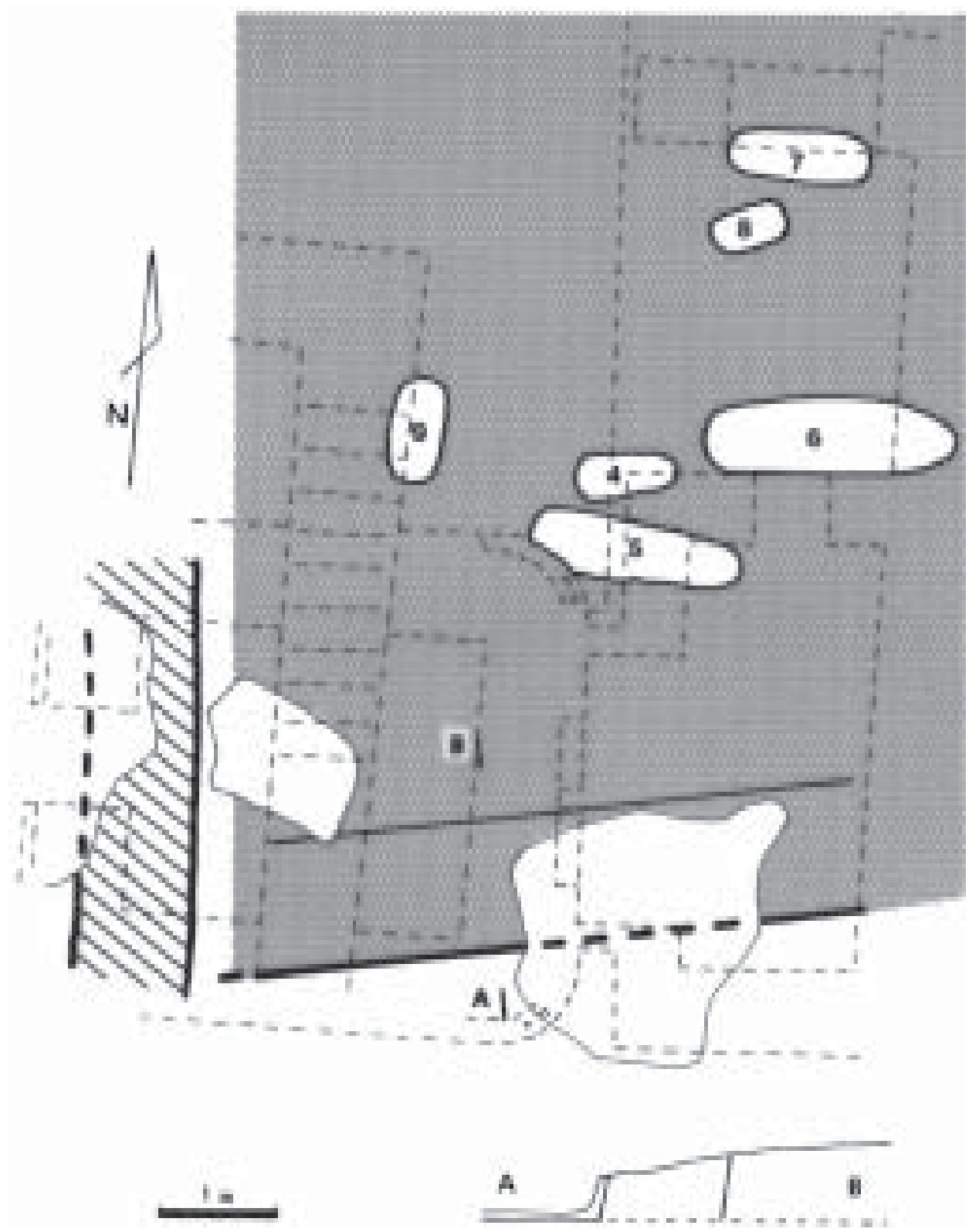

Fig. 8 - Sector III. Plano de las últimas fases de ocupación y de las estructuras superficiales: pozos de huaquero, muro de piedra superficial de la fase 4 (plumeado), tumbas intrusivas de los períodos prehispánicos posteriores, borde de la plataforma de la fase 3-2. Las estructuras arquitectónicas subyacentes están indicadas en trazo interrumpido. Abajo, perfil del borde de la plataforma baja según A-B. 


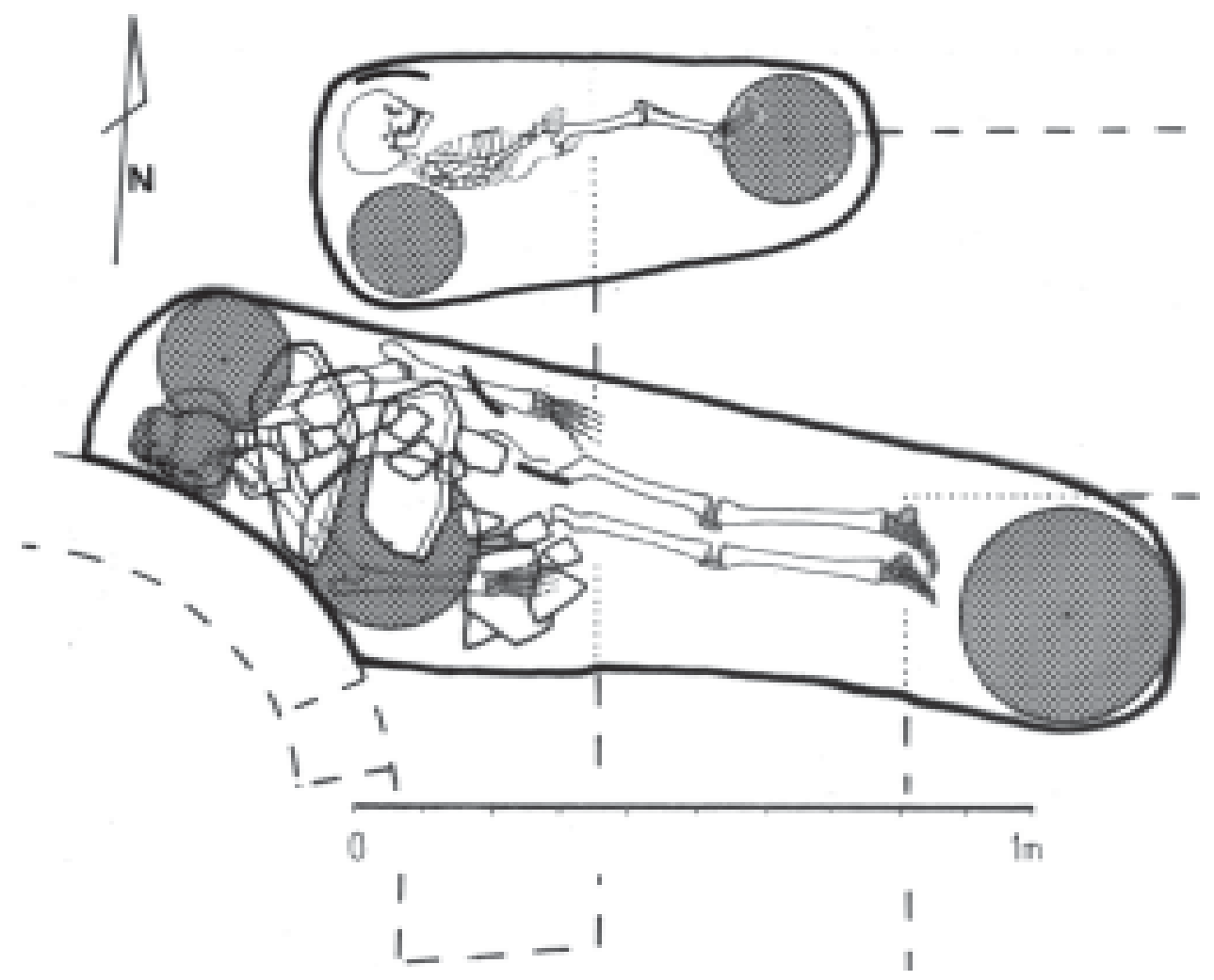

Fig. 9 - Planos de las tumbas $n^{\circ} 4$ et 5 del sector III. Las vasijas están representadas por su silueta en punteado; los tiestos formando tapa y las lajas de piedra están en blanco; tiestos aislados parados están representados por arcos en trazo grueso.

estilo Salinar (Fig. 10, n 3, 4, 6). La más grande tiene bandas verticales anchas más una banda horizontal ancha y dos más delgadas alrededor del cuello ( $\left.n^{\circ} 4\right)$. Las dos ollas pequeñas tienen decoración del tipo con bandas delgadas verticales en grupos de cuatro. Los tiestos esparcidos sobre el cuerpo han permitido reconstruir parte del cuerpo de una olla más grande, posiblemente del mismo tipo que el $\mathrm{n}^{\circ} 3$ pero sin decorar $\left(n^{\circ} 5\right)$. La pequeña vasija encontrada cerca de la cara del individuo es la única que se aparta del tipo "olla utilitaria" que forma el ajuar funerario de estas tumbas $\left(n^{\circ} 7\right)$. Es una vasija antropomorfa, con cuerpo y cuello globulares. Sobre el cuello de la vasija, partes aplicadas forman una nariz, dos ojos redondos y dos orejas estilizadas. Del cuerpo al cuello van dos pequeñas asas redondas formando brazos y con incisiones en las extremidades superiores que figuran los dedos de las manos. El efecto es el de dos manos aplicadas sobre la boca. Sobre la parte superior del cuerpo, bandas delgadas blancas en triángulos parecen figurar una decoración de vestido. 


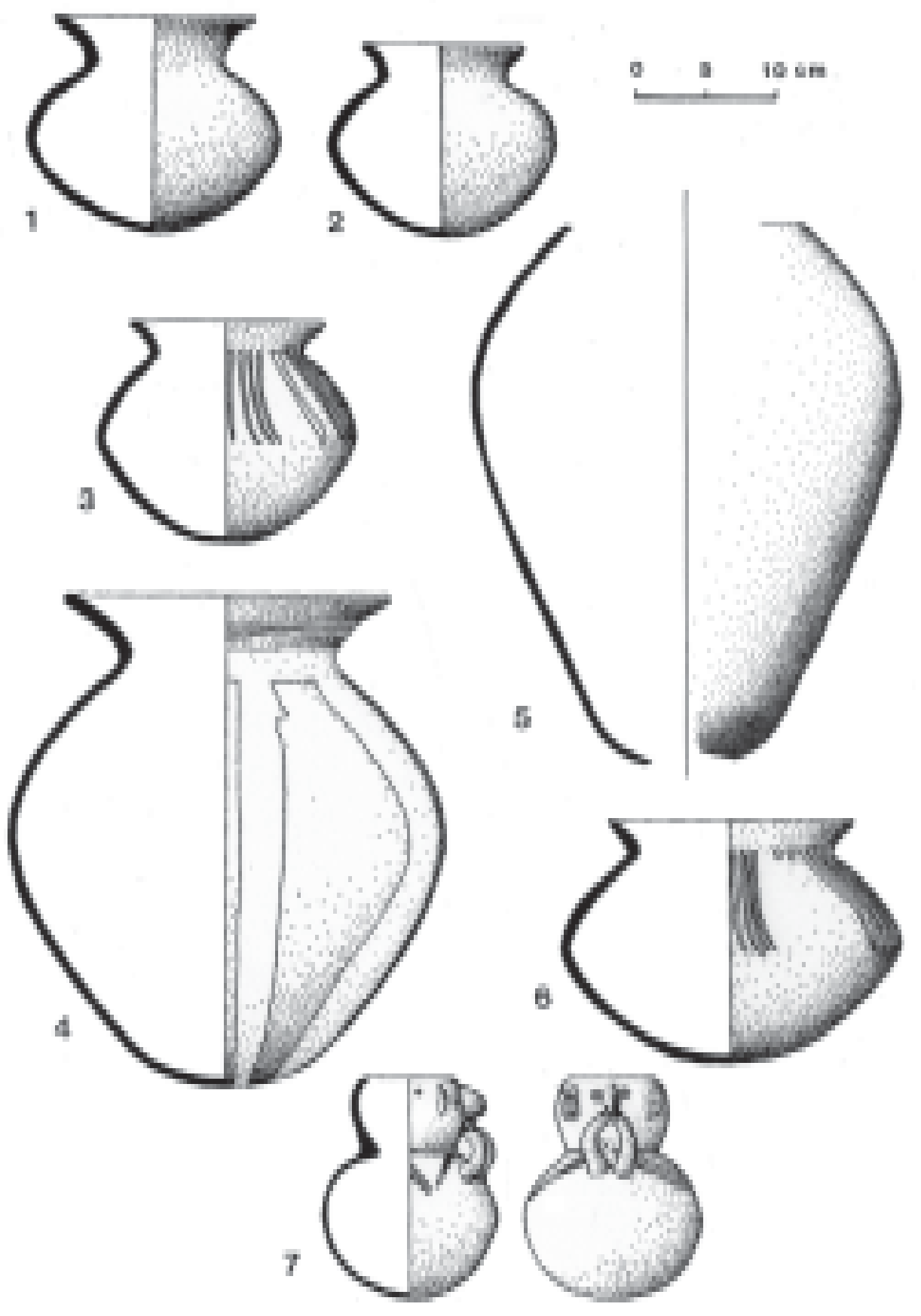

Fig. 10 - Ceramios de la tumba $n^{\circ} 4\left(n^{\circ} 1\right.$ y 2$)$ y de la tumba $n^{\circ} 5\left(n^{\circ} 3,4,5,6,7\right)$. 


\section{2. 3. La tumba $^{\circ} 6$}

Esta tumba se encuentra a menos de medio metro al este de la tumba $n^{\circ} 4 \mathrm{y}$ pegada a uno de los muros que forman las "alas" exteriores del edificio cuadrado de esquinas redondas (Fig. 11). Es una fosa alargada, orientada Este-Oeste, de aproximadamente $2 \mathrm{~m}$ de largo sobre $0,60 \mathrm{~m}$ de ancho y aproximadamente $1 \mathrm{~m}$ de profundidad. Contiene la sepultura de un adulto de alrededor de 1,70 $\mathrm{m}$ de altura, echado en decubito lateral izquierdo, con la cabeza en la extremidad oeste y la cara mirando hacia el norte. El cadáver está apoyado contra la pared norte de la fosa para dejar el espacio a las vasijas de ofrendas a todo lo largo de aquella. Son cuatro ollas de cuello expandido (Fig. 13, ${ }^{\circ} 1$ a 4), una sin decorar y con un cuerpo más alargado en la extremidad este $\left(n^{\circ} 1\right)$, las otras tres con decoración de bandas anchas $\left(n^{\circ} 2,3,4\right)$. Adicionalmente había, en el lado sur, un grupo de grandes tiestos de cerámica a la altura de la cabeza y un tiesto aislado a la altura de la pelvis.

\section{2. 4. Tumba $n^{\circ} 7$}

Las tumbas $n^{\circ} 7$ y 8 se ubican en la extremidad norte de la excavación del sector III y están muy cerca una de otra, un poco a la manera de las tumbas $n^{\circ} 4$ y 5 , observándose la misma ligera desviación en los ejes de orientación de las fosas que en las primeras (Fig. 12). La tumba $n^{\circ} 7$, al norte, tiene un eje orientado Este-Oeste y está situada sobre el umbral sobrealzado que existe a la extremidad del muro largo norte-sur, entre dos posibles pilares dispuestos en dirección Este-Oeste. Esta fosa tenía 1,10 m de largo sobre 0,40 m de ancho y $0,80 \mathrm{~m}$ de profundidad. Contenía el esqueleto de un niño de una altura aproximada de $1,10 \mathrm{~m}$, dispuesto aparentemente en decubito lateral izquierdo, con la cabeza en la extremidad oeste y la cara torcida hacia arriba. Estaba acompañado por una olla de cuello expandido sin decorar, incompleta (Fig. 12, $\mathrm{n}^{\circ}$ 5), ubicada al lado de las piernas, y cuya forma ha podido ser reconstruida en el dibujo.

\section{2. 5. Tumba $n^{\circ} 8$}

Esta tumba se encuentra a $20 \mathrm{~cm}$ al sur de la anterior y comprende una fosa de un poco más de $0,60 \mathrm{~m}$ de largo sobre $0,35 \mathrm{~m}$ de ancho y 0,70 a 0,80 $\mathrm{m}$ de profundidad (Fig. 12). El eje de la fosa está netamente desviado en relación con las anteriores, siendo en dirección Este-Noreste-Oeste-Suroeste. La fosa contenía el cadáver de un niño cuya parte superior sola era visible. Es posible que un pozo de huaquero haya destruido la parte oriental de la sepultura. Acompañaba al niño una sola vasija semejante a las otras ollas de cuello expandido de las tumbas anteriores pero incompleta, sin que se pueda estimar si eso es el producto de la huaquería o si esta vasija estaba originalmente así (Fig. 13, n 6). Esta ultima hipótesis tiene más probabilidad únicamente por el hecho que un tiesto de cerámica aislado cubría directamente (aunque parcialmente) esta vasija, sin posible interposición de un espacio para el cuello de la olla.

\section{2. 6. $T u m b a n^{\circ} 9$}

Esta última tumba del sector III está aislada del punto de vista cronológico así como por su ubicación y orientación (Fig. 8). Se encontraba en la parte occidental de la 

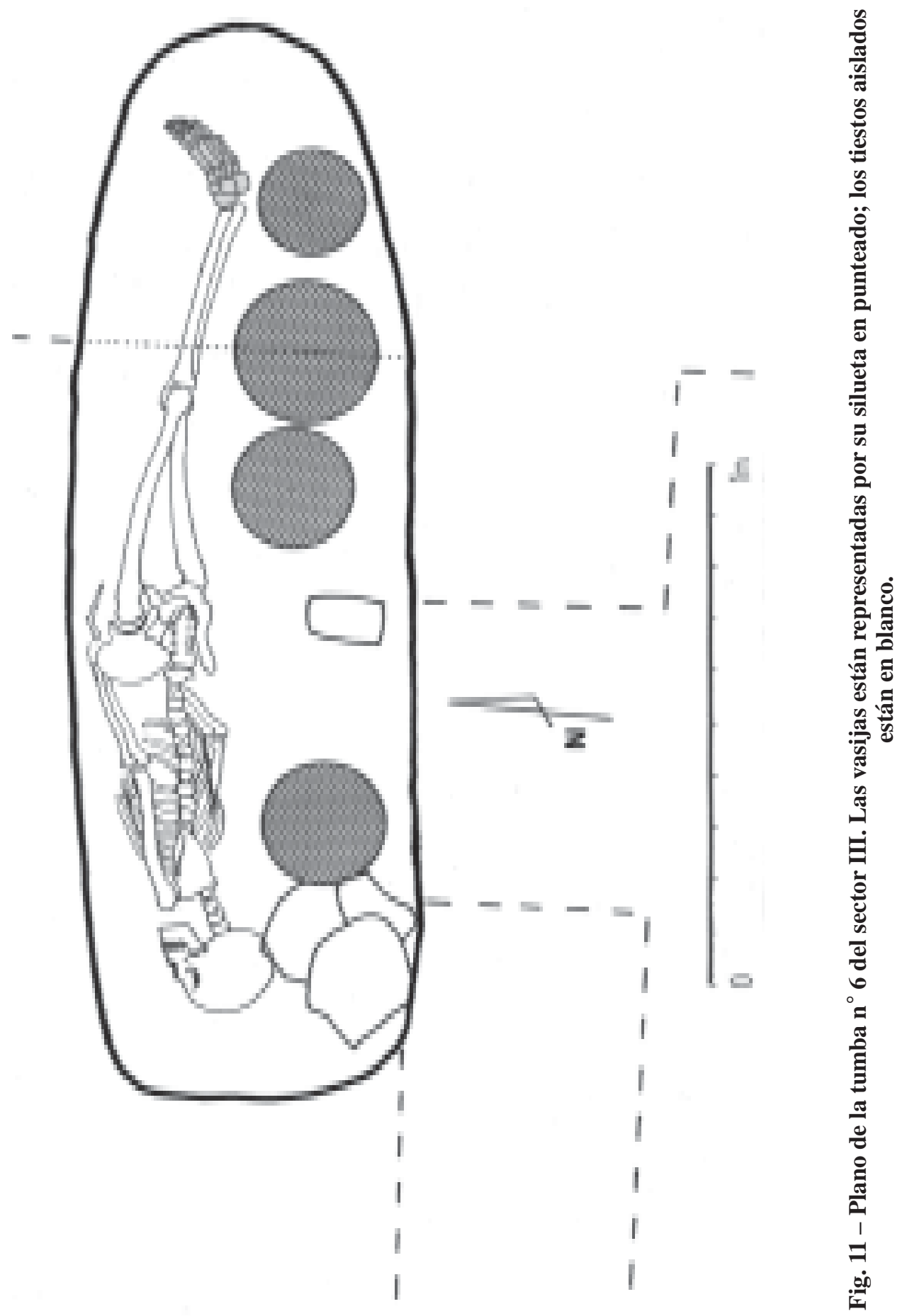


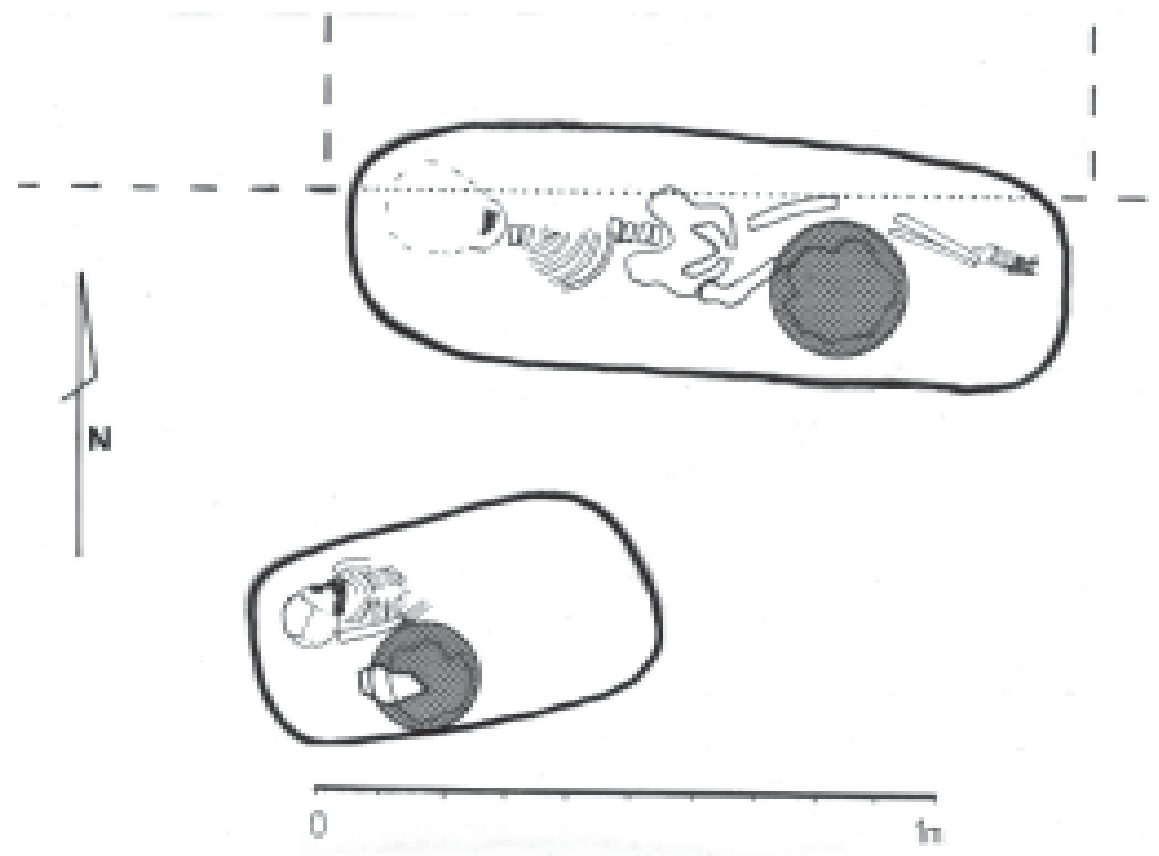

Fig. 12 - Planos de las tumbas $n^{\circ} 7$ et 8 del sector III. Las vasijas están representadas por su silueta en punteado; los tiestos aislados están en blanco.

zona excavada, encima de los primeros peldaños de la escalera de orientación NorteSur que cortaba el cuarto cuadrado de esquinas redondas (fase 3-1 de la arquitectura: Chauchat et al., en preparación). La fosa, orientada Norte-Sur, no se distinguía bien del sedimento circundante pero se evalúa que tenía un poco menos de $1 \mathrm{~m}$ de largo por 0,50 $\mathrm{m}$ de ancho y 0,50 de profundidad (Fig. 14). El esqueleto era de un adulto en decubito lateral izquierdo, con las piernas fuertemente flexionadas y los brazos extendidos en la misma dirección de modo que las manos se encontrababan junto a los pies. La cabeza, con la cara mirando hacia el suroeste, se encontraba en la extremidad sur de la fosa. El cráneo estaba levemente deformado por achatamiento occipital; la columna vertebral tenía huellas de artritis. El ajuar funerario constaba de dos vasijas cerca de la cabeza: el tazón vertido sobre el cráneo y la botella con gollete y asa justo detrás, así como pedazos o huellas de cobre, uno posiblemente cerca de un hombro o del cuello del cadáver y dos más en la parte inferior del cuerpo, cerca de las manos y los pies.

La botella, cuya asa falta, tiene sobre la parte superior del cuerpo un diseño formando volutas en relieve obtenido por molde (Fig. 15, $\mathrm{n}^{\circ}$ 1). El tazón, hecho también con molde, lleva una cruz en la cara inferior de la base $\left(n^{\circ} 2\right)$. Estos dos objetos pertenecen claramente al período Intermedio Tardío, más específicamente al estilo Chimú temprano (Carol Mackey, comunicación personal, 1972). 

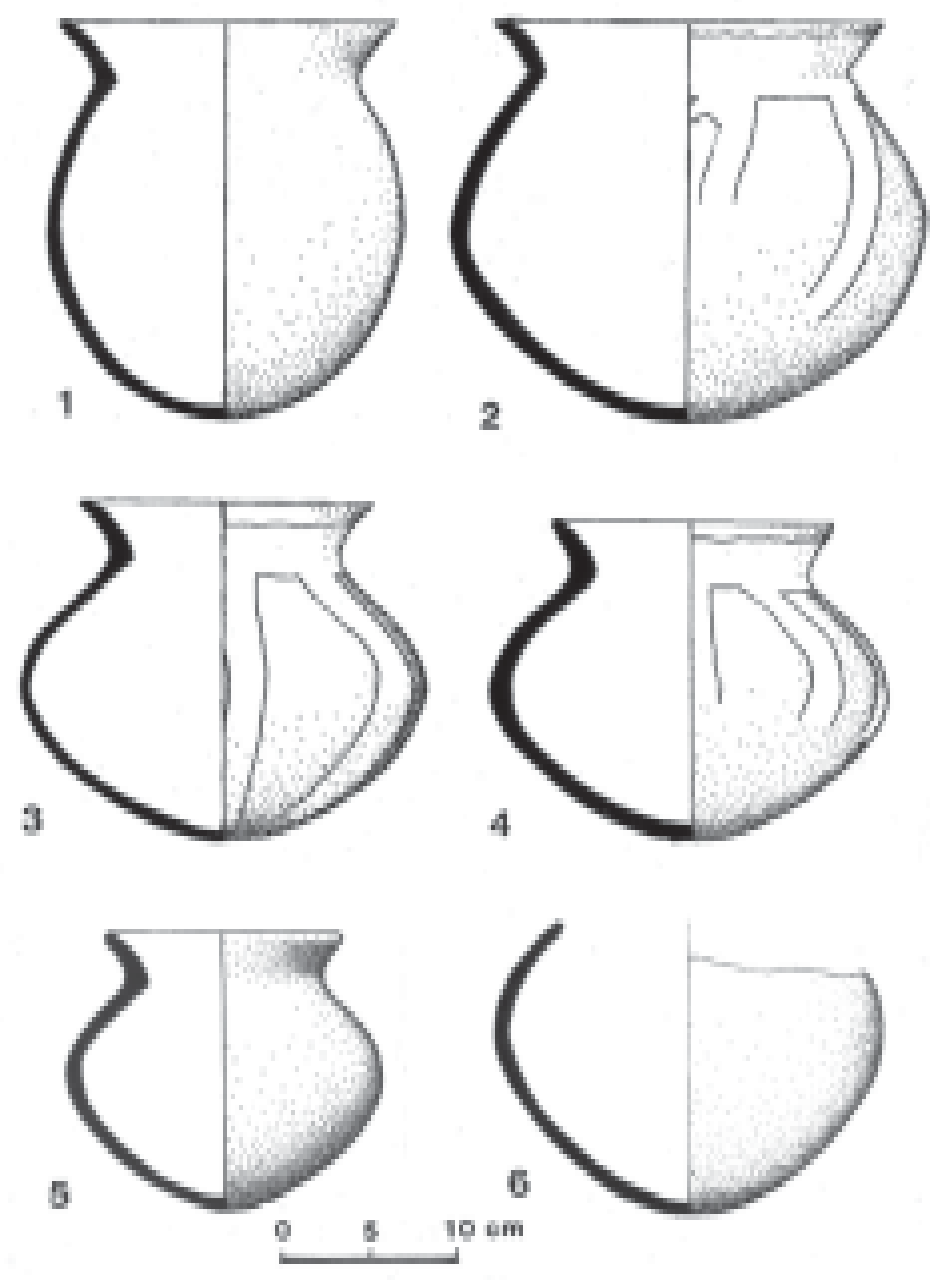

Fig. 13 - Ceramios de la tumba $n^{\circ} 6\left(n^{\circ} 1,2,3,4\right)$, de la tumba $n^{\circ} 7\left(n^{\circ} 5\right)$ y de la tumba $n^{\circ} 8\left(n^{\circ} 6\right)$.

\section{CONCLUSIONES}

La Huaca Herederos Chica ha sido construida y ocupada principalmente durante el Período Inicial y el Horizonte Temprano como posible sitio de vivienda y sitio ceremonial. Aparentemente, después del Horizonte Temprano, no hubo mayores rasgos arquitectónicos asociados a ocupaciones ulteriores salvo algunas hileras de adobes rectangulares adosados a la plataforma occidental. Sin embargo, el lote abundante de cerámica encontrado en la superficie del sector I contiene algunos tiestos típicos de épocas posteriores, particularmente algunos bordes expandidos Salinar, un tiesto con 

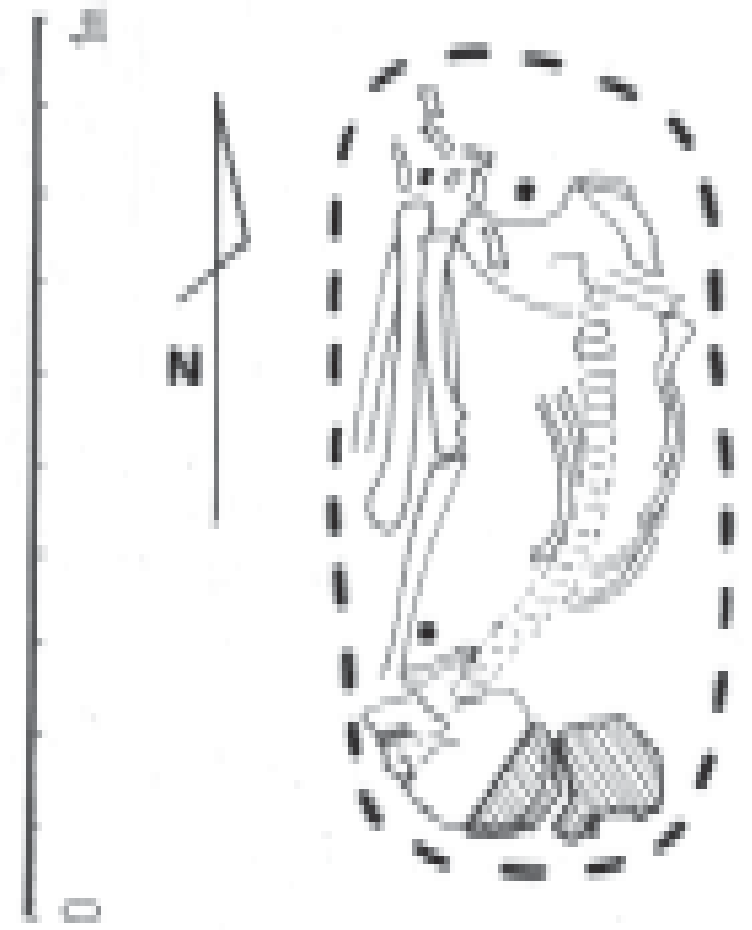

Fig. 14 - Plano de la tumba $n^{\circ} 9$ del sector III. Las vasijas están representadas por su silueta en punteado.

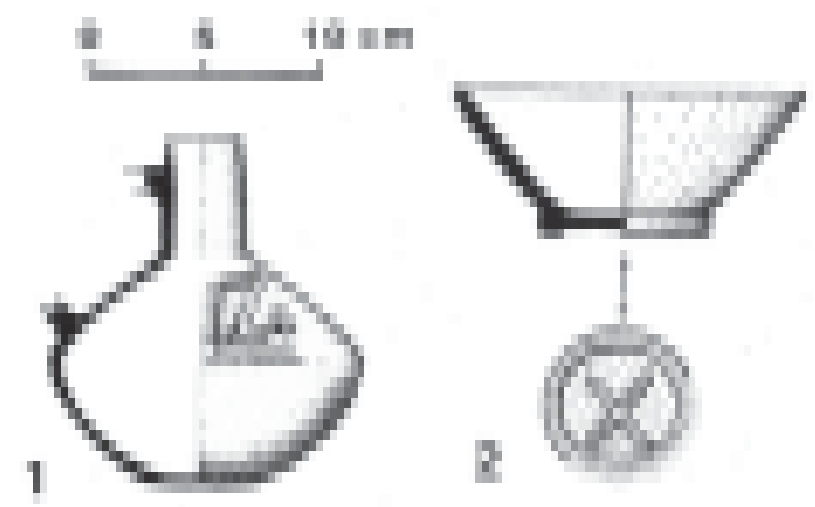

Fig. 15 - Ceramios de la tumba $n^{\circ} 9$ del sector III. 
decoración negativa Gallinazo, algunos tiestos Moche y Chimú decorados. Además, se encontró un tiesto del tipo Layzon red on white (Terada \& Onuki, 1979: 104 y color plate 3B, a-b) que señala una importación de los Andes de Cajamarca. En el sitio Salinar de Cerro Arena, del mismo valle de Moche, E. Mujica encontró también restos de este estilo (Mujica, 1984). Es posible que la ocupación del sitio en estas épocas sea mayormente funeraria como lo muestran las tumbas intrusivas descritas en este artículo.

Sin embargo, la mayoría de las tumbas encontradas pertenecen al período Salinar, inmediatamente posterior al Horizonte Temprano. Tanto el ajuar cerámico como su disposición en las fosas sepulcrales muestra un conjunto ritual común a todas las tumbas. Las fosas son cavadas en orientación Este-Oeste; en la mayoría de los casos, el cadáver está dispuesto en decubito lateral, mayormente izquierdo, es decir volteado hacia el Norte, y con la cabeza al Oeste; pero existen dos excepciones donde la cara del difunto mira al Sur. Las vasijas se disponen a lo largo de la fosa en el espacio dejado libre por el cuerpo, a veces sobre el cuerpo mismo. Las ollas de cocina que han sido depositadas en las tumbas están, en su mayoría, cuidadosamente dispuestas de manera a quedar paradas, y cubiertas por tiestos de cerámica y, por lo tanto, han podido contener algún producto alimenticio, líquido o sólido. Otros tiestos de cerámica cubrían o protegían la cabeza del muerto, pero en algunos casos estaban dispuestos al lado, quizás para proteger un objeto en materia orgánica desaparecido (¿tejido?). Una diferencia entre las tumbas del sector I y aquellas del sector III es la presencia de un nicho en el extremo occidental de las tumbas $n^{\circ} 1$ a 3 mientras no existe este rasgo en las del sector III. Estas variaciones podrían testimoniar de diferencias en los rituales existentes entre varios grupos contemporáneos o simplemente de evoluciones temporales dentro de las prácticas funerarias. En todo caso, el uso del yacimiento como cementerio parece claramente haber sido realizado por sectores quienes presentan una gran coherencia interna debida a relaciones familiares o a una relativa contemporaneidad entre las tumbas cercanas. Más allá, el conjunto de los entierros tiene sin embargo una cierta unidad basada en la presencia en los dos sectores, de individuos de diversos sexos y edades, de condición social aparentemente no elitista.

La cerámica muestra pocos rasgos significativos, aparte del único ceramio que destaca por una relativa originalidad de forma y decoración aunque siendo típico del período Salinar (Fig. 10, n $^{\circ}$ ). Algunas vasijas son sin decorar; las decoradas muestran dos tipos, uno con bandas blancas anchas, el otro con grupos de bandas delgadas paralelas, sin que una u otra clase de decoración sea exclusiva en cada tumba. Además, no solamente las formas muestran un cambio con el período anterior sino que la pasta muestra una clara innovación técnica en relación con la cerámica del Horizonte Temprano, por los colores anaranjados de la superficie y a menudo rojo con matices hasta el violáceo, visibles en el interior de las roturas. Se debe destacar, de nuevo, que ninguna de estas tumbas del estilo Salinar evidencia ser de miembros de una elite. Más bien, la predominancia de ollas utilitarias, algunas con huellas claras de uso (presencia de hollín en la parte inferior) indica que estamos en presencia de entierros de una clase pobre, quizás agricultores o gente dedicados al mantenimiento del canal Vichansao cercano.

La única tumba del período Intermedio Tardío denota una ruptura con los patrones de enterramientos del Intermedio Temprano. El eje del largo de la fosa es Norte-Sur en 
lugar de ser Este-Oeste; el cadáver tiene las piernas flexionadas fuertemente, el cráneo está deformado (ninguno de los cráneos de las tumbas Salinar parece tener deformación) $y$, entre las ofrendas, existen pedazos de cobre cerca de la cabeza y de las extremidades de los miembros, costumbre que aparece ya en el período Moche donde pedazos de cobre se ponen en la boca, en las manos y, a veces, bajo los pies de los difuntos. Los fragmentos metalúrgicos recolectados en esta tumba podrían corresponder a piezas de forma rectangular denominados "naipes". Su uso como ajuar funerario ya fue señalado en varios sitios del período Intermedio Tardío de la costa norte del Perú, tal como en Batán Grande (fase Sicán tardío) (Shimada, 1985) y en Cerro Nañanique (fase Piura A/B) (Guffroy et al., 1989).

\section{Agradecimientos}

El Chan Chan-Moche Valley Project ha sido financiado por el Peabody Museum of American Archaeology and Ethnology de la Universidad de Harvard, la National Geographic Society, y la National Science Foundation. Agradecemos especialmente a los participantes en las excavaciones, Luis Watanabe, Elías Mujica, James Vreeland, Andrée Paulet, los dibujantes Miguel Alvarez y Carlos Felipe, los topógrafos Japhet Rosell y Willian Yenque, así como a Carol Mackey, Tom y Shelia Pozorski por su ayuda en varias oportunidades.

\section{Referencias citadas}

CHAUCHAT, C., GUFFROY, J. \& POZORSKI, T. G., en preparación - Huaca Herederos Chica, a formative site of the Caballo Muerto complex, Moche Valley, Northern Peru.

DONNAN, C. B. \& MACKEY, C. J., 1978 - Ancient Burial Patterns of the Moche Valley, Peru, 412p.; Austin: University of Texas Press.

GUFFROY, J., HIGUERAS, Á. \& GALDOS, R., 1989 - Construcciones y cementerios del período Intermedio Tardío en Cerro Nañañique (departamento de Piura). Bulletin de l'Institut Français d'Études Andines, 18(2): 209-240; Lima.

LARCO HOYLE, R., 1938 - Los Mochicas, T. 1.; Lima: Casa editorial La Crónica y Variedades S. A.

MUJICA, E., 1984 - Cerro Arena-Layzon: relaciones costa-sierra en el norte del Perú. Gaceta Arqueológica Andina, 10: 12-15; Lima: Instituto Andino de Estudios Arqueológicos.

POZORSKI, T. G., 1976 - Caballo Muerto: A complex of early Ceramic Sites in the Moche Valley, Peru; Austin:, University of Texas. Unpublished Ph. D. Dissertation.

POZORSKI, T. G., 1988 - The Caballo Muerto Complex and its place in the Andean Chronological sequence. Annals of Carnegie Museum, 52: 1-40; Pittsburgh, Pennsylvania: Carnegie Museum of natural History.

SHIMADA, I., 1985 - La Cultura Sicán, caracterización arqueológica. In: Presencia de Lambayeque: 76-133; Chiclayo.

TERADA, K. \& ONUKI, Y., 1979 - Excavations at Huacaloma in the Cajamarca Valley, Peru. Report $n^{\circ} 2$ of the Japanese Scientific Expedition to Nuclear America. University of Tokyo Press.

WATANABE, L., 1976 - Sitios tempranos en el Valle de Moche (Costa Norte del Peru); Lima: Universidad Nacional Mayor de San Marcos. Tesis doctoral no publicada. 
Institut Français d'Études Andines - Pontificia Universidad Católica del Perú-Fondo Editorial - Embajada de Finlandia Pedidos: IFEA, Casilla 18-1217, Lima 18 - Perí, Tel. 4476070 Fax: 4457650 - E-mail: postmasterlifea.org.pe Web: http://www. ifeanet.org 